\title{
RANCANG BANGUN ROBOT PELONTAR SHUTTLECOCK
}

\author{
Rodika $^{1}$, Jamalludin ${ }^{2}$, Handriko $^{3}$, Aryono Priyambudi ${ }^{4}$, Aldi Pranata ${ }^{5}$ \\ ${ }^{1}$ Jurusan Teknik Mesin, ${ }^{2,3,4,5}$ Jurusan Elektronika, \\ Politeknik Manufaktur Negeri Bangka Belitung \\ Kawasan Industri Airkantung Sungailiat, \\ Telp.0717-93586, Fax.0717-93585, r_rodika@ymail.com
}

\begin{abstract}
The design of robot launcher shuttlecock is done by researchers so that the robot produced can help human activity in the field of sports. This throwing robot can be used as a training medium for selftaught players, where practice can be done without a trainer / helpers. Players can practice at any time without being linked with others (trainers / feeders) so that training time can be maximized. The methodology of this tool includes the manufacture and design of hardware and software. The manufacture and design of mechanical hardware involves the construction of aluminum frames, with actuators in the form of motors and pneumatic systems while for the design and manufacture of electronics hardware includes the manufacture of control circuits. Preparation and design of software include programming mikrokontroler ATMega128. From the test results, the robot can throw shuttlecock. Robot can do 6 mode service ie service mode near, far, left, right, random and join with average success percentage equal to $93,35 \%$.
\end{abstract}

Keywords: microcontroller, service, shuttlecock

\begin{abstract}
Abstrak
Rancang bangun robot pelontar shuttlecock ini dilakukan peneliti agar robot yang dihasilkan dapat membantu aktivitas manusia dalam bidang olahraga. Robot pelontar ini dapat digunakan sebagai media latihan bagi pemain secara otodidak, dimana latihan dapat dilakukan tanpa juru latih/pembantu. Pemain dapat berlatih setiap waktu tanpa keterkaitan dengan orang lain (juru latih/pengumpan) sehingga waktu latihan dapat dimaksimalkan. Metodologi alat ini meliputi pembuatan dan perancangan hardware dan software. Pembuatan dan perancangan hardware mekanik meliputi pembuatan konstruksi dengan kerangka aluminium, dengan aktuator berupa motor dan sistem pneumatic sedangkan untuk perancangan dan pembuatan hardware elektronika meliputi pembuatan rangkaian kontrol. Pembuatan dan perancangan software meliputi pemrograman mikrokontroler ATMega128. Dari hasil uji coba, robot dapat melontarkan shuttlecock. Robot dapat melakukan 6 mode service yakni mode service dekat, jauh, kiri, kanan, acak dan gabung dengan rata-rata persentase keberhasilan sebesar $93,35 \%$.
\end{abstract}

Kata kunci: mikrokontroler, service, shuttlecock

\section{PENDAHULUAN}

Perkembangan bidang robotika pada saat ini semakin pesat bahkan robot banyak digunakan untuk membantu meringankan kegiatan manusia. Ilmu robotika di Indonesia sendiri sudah ada dan berkembang sejak tahun 1980-an. Pesatnya perkembangan robot telah banyak membantu berbagai aktivitas manusia dalam berbagai kegiatan, misalkan untuk bidang olahraga telah membantu dalam bidang latihan maupun pertandingan. Dukungan ilmu pengetahuan turut banyak membantu atlet-atlet untuk berprestasi sehingga mulai dari pencarian bakat hingga latihan. Dan untuk mendukung hal tersebut, terutama pada bidang olah raga bulutangkis akan dibuat robot pelontar shuttlecock. Robot ini dapat digunakan untuk berlatih secara mandiri, dimana bola dapat dilontarkan secara otomatis untuk melatih skill atlet bulutangkis.

Dengan robot bulutangkis sebagai media latihan ini pemain dapat berlatih otodidak, dimana latihan dapat dilakukan tanpa juru latih/pembantu yang mengumpankan shuttlecock. Pemain dapat 
berlatih setiap waktu tanpa keterkaitan dengan orang lain (juru latih/pengumpan) sehingga waktu latihan dapat dimaksimalkan.

\section{METODE PENELITIAN}

Dalam penelitian ini langkah-langkah yang dilakukan akan disajikan dalam diagram alir pada Gambar 1 berikut ini:

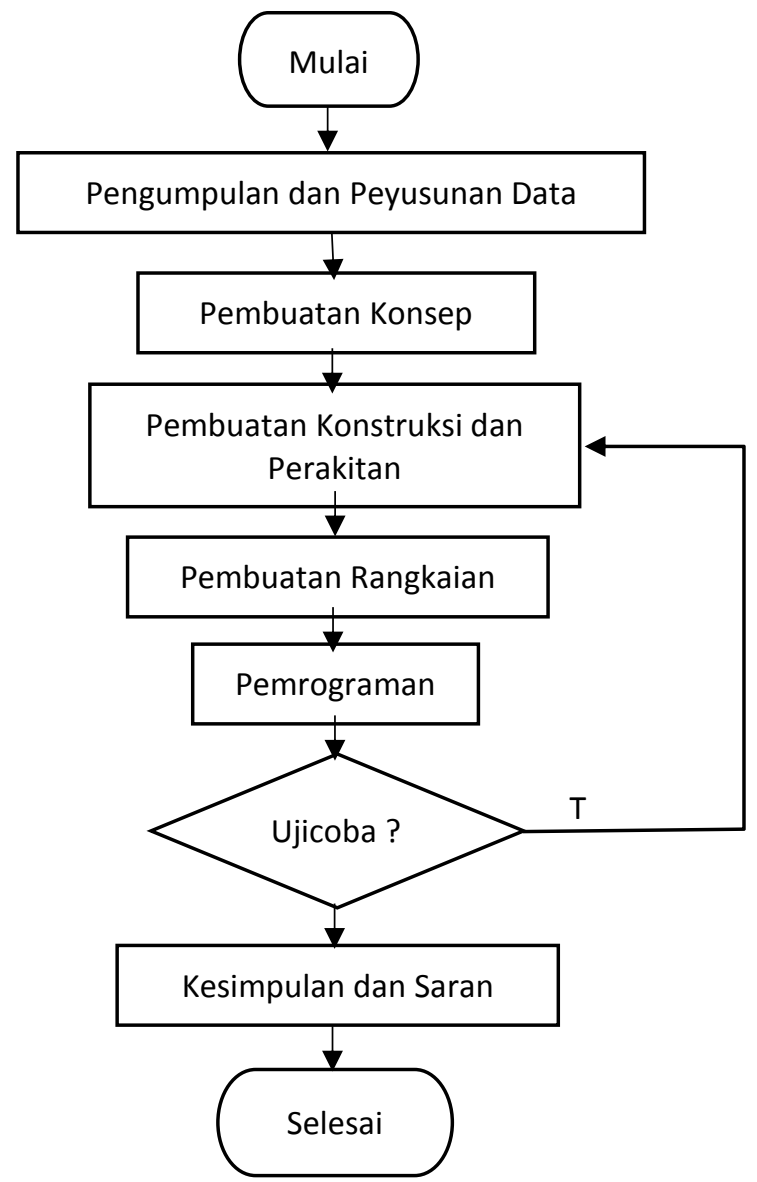

Gambar 1. Diagram Alir Tahapan Penelitian

\section{HASIL DAN PEMBAHASAN}

\subsection{PERANCANGAN}

Pada tahapan ini, dari data yang sudah terkumpul dapat dijadikan referensi dalam proses perancangan gambar konstruksi dari robot. Data-data yang menjadi pertimbangan dalam perancangan antara lain dapat dilihat pada tabel 3.1.

Tabel 3. 1 Tabel Daftał Kebutuhan

\begin{tabular}{ll}
\hline No. & \multicolumn{1}{c}{ Uraian } \\
\hline 1. Service lambung \\
2. Service dapat diarahkan ke kiri dan ke kanan \\
3. Service dapat diarahkan jauh dan dekat \\
4. Service dapat mode gabungan dan mode acak \\
5. Berat maksimun robot tidak lebih dari $25 \mathrm{Kg}$
\end{tabular}




\section{Ukuran maksimum robot $1000 \mathrm{~mm} \times 1000 \mathrm{~mm} \times 1600 \mathrm{~mm}$}

Dari data-data yang sudah terkumpul lalu dirangkum menjadi suatu daftar kebutuhan, dari daftar tersebut dapat dijadikan referensi untuk merancang robot pelontar shuttlecock. Hasil rancangan dapat dilihat pada gambar 3.1.

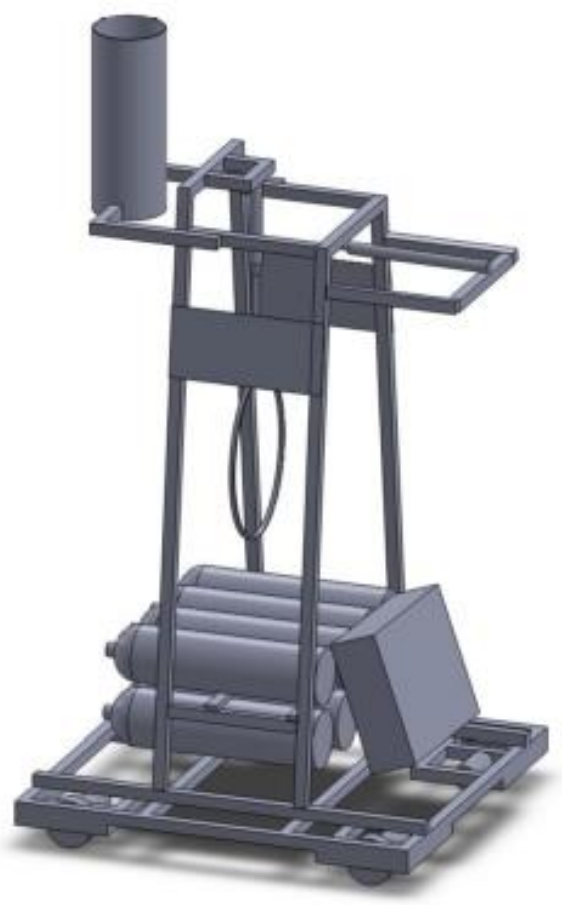

Gambar 3.1. Gambar Rancangan Robot pelontar shuttlecock

\subsection{Bahan}

Pada tahapan ini akan ditentukan jenis bahan yang akan digunakan, dimana dimensi dan berat diperitungkan dalam pemilihan bahan. Tidak hanya itu waktu pengerjaan dan harga juga menjadi pertimbangkan. Dari pertimbangan tersebut didapat kriteria bahan yang akan digunakan dalam pembuatan konstruksi adalah menggunakan bahan aluminium kotak. Pertimbangannya adalah selain ringan, mudah dikerjakan, mudah didapat dan harga terjangkau.

\subsection{Pembuatan Dan Perakitan}

Pembuatan konstruksi dan perakitan disini ditekankan pada pembuatan bagian-bagian robot. Pembuatan bagian robot dilakukan melalui proses permesinan sesuai gambar yang telah dibuat sebelumnya. Bagian-bagian yang telah dibuat kemudian dirakit menjadi satu kesatuan yang membangun konstruksi robot. Hasil perakitan robot dapat dilihat pada gambar 3.3. 


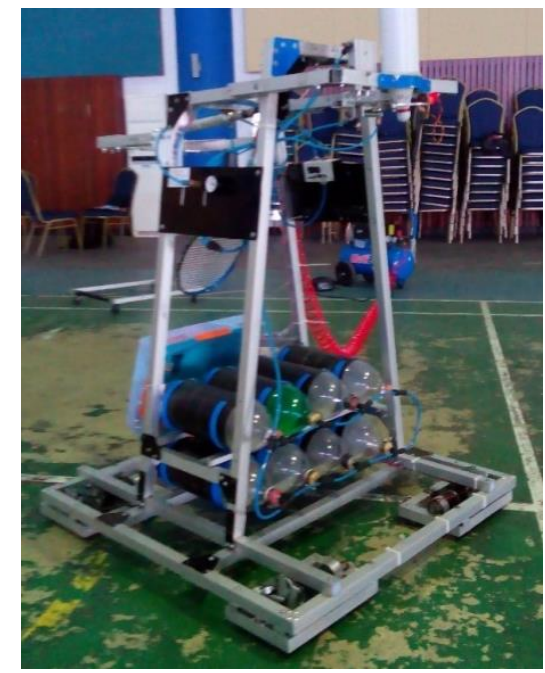

Gambar 3.3 Robot Yang Telah Di Rakit

\subsection{Pembuatan Rangkaian Elektronika}

Pembuatan rangkaian elektronika yaitu membuat rangkaian (layout $P C B$ ) menggunakan software kemudian melalui proses etching dan penyolderan komponen elektronika tersebut ke papan $P C B$ serta pengkoneksiaan antar modul dengan mengguakan kabel. Blog diagram hardware robot bulutangkis dapat dilihat pada Gambar 3. 4 .

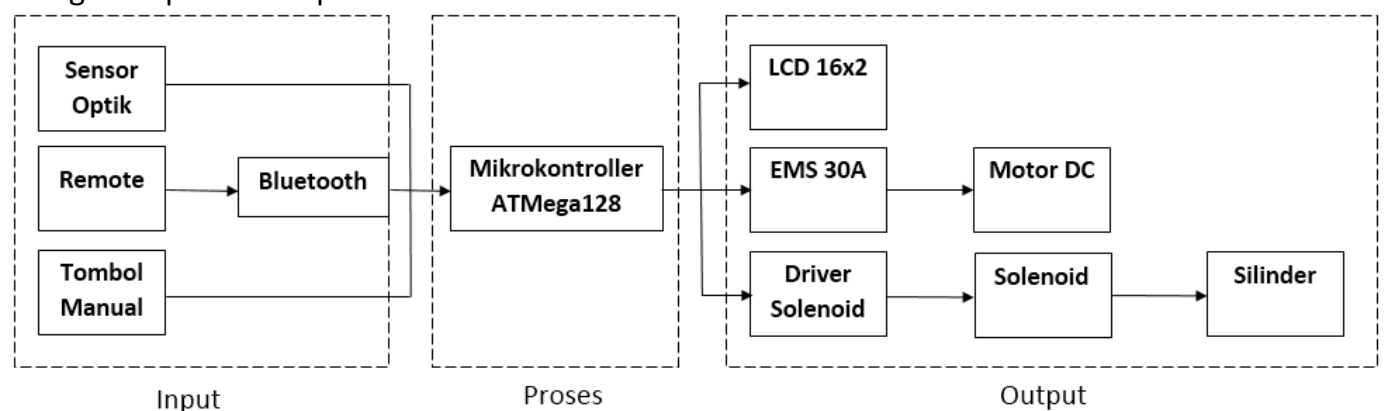

Gambar 3. 4 Blok Diagram Hardware

\subsection{Uji Coba}

Uji coba dilakukan setelah semua konstruksi telah selesai dibuat dan rangkaian elektronika sudah terpasang pada robot. Pengujian dilakukan dengan mencoba setiap mode yang tersedia pada alat. Percobaan dilakukan dengan melakukan service sebanyak 12 kali (satu set).

Posisi jatuhnya shuttlecock jatuh pada range yang telah di tentukan, yaitu untuk service jauh, kiri dan kanan range yang ditentukan berukuran $150 \mathrm{~cm} \times 150 \mathrm{~cm}$ seperti ditunjukan oleh nomor 1, 2, 3 dan service dekat berada di depan short service line seperti yang ditunjukan oleh nomor 4 dengan besar range $518 \mathrm{~cm} \times 198 \mathrm{~cm}$. Untuk lebih jelas dapat dilihat pada Gambar 3. . 


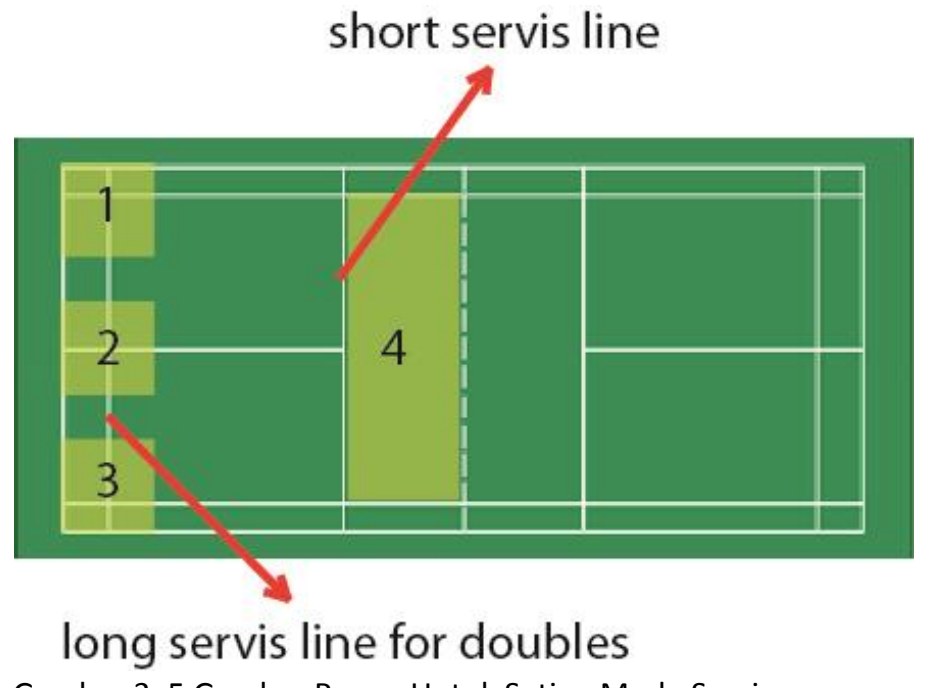

Gambar 3. 5 Gambar Range Untuk Setiap Mode Service

\section{SIMPULAN}

Berdasarkan hasil pengujian dan analisa fungsi terhadap robot bulutangkis ini maka dapat ditarik kesimpulan sebagai berikut:

1. Robot dapat melakukan mode service jauh dengan persentase tingkat keberhasilan $96,67 \%$ dan service dekat dengan persentase tingkat keberhasilan 91,67\%.

2. Robot dapat melakukan mode service kiri dengan persentase tingkat keberhasilan $93,33 \%$ dan service kanan dengan persentase tingkat keber-hasilan 91,67\%.

3. Robot dapat melakukan mode service gabung dengan persentase tingkat keberhasilan $93,33 \%$ dan mode service acak dengan persentase tingkat keberhasilan 91,33\%.

\section{DAFTAR PUSTAKA}

[1]. Wall Street Daily, Badminton Robot Champions Energy Efficiency, diakses pada 13 juli 2015, Available: http://www.oilandenergydaily.com/2013/-06/24/badminton-robot/

[2]. Apollo Badminton Trainer, Products, diakses pada 22 Juni 2015, Available: http://www.badmintonmachine.com/products

[3]. Sularso dan Kiyakatsu Suga, "Dasar Perancanaan dan Pemilihan Elemen Mesin", Edisi Keduabelas, Jakarta: PT. Pradnya Paramita, 2008

[4]. Sularso dan Suga, Kiyokatsu, "Dasar Perancanaan dan Pemilihan Elemen Mesin", Edisi kedelapan, Jakarta: PT. Pradnya Paramita, 1994.

[6]. Innovtive Electronics, DT-AVR ATMEGA128L BOOTLOADER MICRO SYSTEM, diakses pada 22 Juni 2015, Available: http://www.innovative-electronics.com/index.php?pg=ie pdet\&idp=23 